\title{
A global non-hydrostatic model study of a downward coupling through the tropical tropopause layer during a stratospheric sudden warming
}

\author{
N. Eguchi ${ }^{1}$, K. Kodera ${ }^{2}$, and T. Nasuno ${ }^{3}$ \\ ${ }^{1}$ Research Institute for Applied Mechanics, Kyushu University, Kasuga, Japan \\ ${ }^{2}$ Solar-Terrestrial Environment Laboratory, Nagoya University, Nagoya, Japan \\ ${ }^{3}$ Research Institute for Global Change, Japan Agency for Marine-Earth Science and Technology, \\ Yokohama, Japan
}

Correspondence to: N. Eguchi (nawo@riam.kyushu-u.ac.jp)

Received: 21 February 2014 - Published in Atmos. Chem. Phys. Discuss.: 13 March 2014

Revised: 10 November 2014 - Accepted: 16 November 2014 - Published: 13 January 2015

\begin{abstract}
The dynamical coupling process between the stratosphere and troposphere in the tropical tropopause layer (TTL) during a stratospheric sudden warming (SSW) in boreal winter was investigated using simulation data from a global non-hydrostatic model (NICAM) that does not use cumulus parameterization. The model reproduced well the observed tropical tropospheric changes during the SSW, including the enhancement of convective activity following the amplification of planetary waves. Deep convective activity was enhanced in the latitude zone $20-10^{\circ} \mathrm{S}$, in particular over the southwest Pacific and southwest Indian Ocean. Although the upwelling in the TTL was correlated with that in the stratosphere, the temperature tendency in the TTL changed little due to a compensation by diabatic heating originating from cloud formation. This result suggests that the stratospheric meridional circulation affects cloud formation in the TTL.
\end{abstract}

\section{Introduction}

There have been many studies on the interaction between the stratosphere and troposphere in the tropical tropopause layer (hereafter, TTL), which is typically located at 14$19 \mathrm{~km}$ altitude or $150-90 \mathrm{hPa}$ (Highwood and Hoskins, 1998; Fueglistaler et al., 2009), with stratospheric water vapour variation on interannual and seasonal timescales (cf. Randel and Jensen, 2013) being an important topic. Possible im- pacts of the recent stratospheric cooling trend on the troposphere, such as an increase of intensity in tropical cyclones, are currently the subject of discussion (Emanuel et al., 2013; Ramsay, 2013). However, it is difficult to separate the stratospheric effect on the troposphere from other factors for longterm variations, such as a warming of the ocean.

Here, we focus on changes in the troposphere, especially in the TTL, during a stratospheric sudden warming (hereafter, SSW) event, which drastically modifies the stratospheric circulation (Brewer-Dobson (BD) circulation) in the space of a week because the tropical convection and the general circulation (the Hadley and Walkerwere cells) rapidly changed during the strong SSW events found by some previous observational studies (e.g. Eguchi and Kodera, 2007, 2010; EK10). Further, because of the short-duration phenomenon, the impact of SSW on the tropical troposphere can be separated from long-term variability such as the Madden-Julian Oscillation (MJO), El Nino-Southern Oscillation (ENSO) or the Quasi-Biennial Oscillation (QBO). However, it is still not clear how the connection between the stratosphere and troposphere occurs and how it modulates the convective activity during SSW events.

This is largely due to a lack of global observations of vertical velocity in the TTL. Ueyama et al. (2013) showed that the temperature tendency in the stratosphere can be used as a proxy for the vertical motion (i.e. the strength of $\mathrm{BD}$ circulation). However, this relationship does not hold below the 
tropopause, where diabatic heating due to cloud formation cancels adiabatic cooling, as will be shown later.

Data from numerical simulation are useful for examining vertical velocity in the TTL. Thuburn and Craig (2000) used momentum forcing in a simplified global general circulation model (GCM) to show that a change in the stratospheric meridional circulation modified cumulus heating in the TTL as well as the tropopause height. Kodera et al. (2011) constructed a more realistic forecast experiment by incorporating an atmospheric blocking-type circulation anomaly in the North Atlantic in the initial conditions to amplify planetary waves and produce strong BD circulation later in the stratosphere. The results showed similar effects in the tropics to those seen in observational studies; that is, the tropical convective activity was enhanced zonally, especially in the Southern Hemisphere (SH), and cooling at the tropopause region associated with the SSW event was capable of modulating tropical convective activity.

These results suggest that convection plays an important role in the stratosphere-troposphere coupling in the tropics. In these models, however, the effects of convection were not explicitly treated but were represented by cumulus parameterization. Thus, dependence on the parameterization was unavoidable. Furthermore, examination of thermodynamic processes in the TTL using the higher-resolution GCM is desired to clarify the coupling process between the stratosphere and troposphere, where the thermodynamic balance is complicated. In the present study, convective change during an SSW event that occurred in January 2010 is investigated using high-resolution global simulation data from a global nonhydrostatic model, NICAM (non-hydrostatic icosahedral atmospheric model) (Satoh et al., 2008, 2014), in which a cumulus parameterization was not employed. This allows the discussion of the dynamic and thermodynamic changes in the TTL without any prescribed relationship between dynamics and moist convection. A case study using such highresolution simulation data has the advantage of capturing the fine vertical and temporal structures of the TTL during the SSW event, which might be smoothed away in a statistical analysis of a huge number of events occurring under a range of conditions.

The remainder of the paper is organized as follows. The next section deals with the NICAM simulation data (Sect. 2), Sect. 3 shows the SSW event simulated in NICAM and the dynamical variability in the stratosphere and troposphere during the SSW. A summary and discussion of the results are given in Sect. 4.

\section{Analysis data}

The numerical simulation was conducted using NICAM, the global non-hydrostatic model with a horizontal mesh size of $14 \mathrm{~km}$ and 40 vertical levels. Kodama et al. (2012) assessed cloud signals in NICAM simulations and demonstrated that the gross behaviour of clouds can be statistically reproduced with $14 \mathrm{~km}$ mesh size, although individual clouds are not sufficiently resolved. The main purpose of the present study is not a realistic presentation of an individual cloud but the investigation of diabatic heating processes in the TTL without any prescribed relationship between convection and dynamics as assumed in a cumulus parameterization. The use of $14 \mathrm{~km}$ horizontal mesh size and $38 \mathrm{~km}$ model top is marginal to a TTL study, which will be followed by numerical studies with more suitable set-ups (Satoh et al. 2014). Nevertheless, the BD circulation and the seed of the SSW events included in the initial data, which were interpolated from an objective analysis, led to spontaneous occurrences of reasonable atmospheric circulation and convection in the model for the simulation period, as shown in Sect. 3.

The model top was at $38 \mathrm{~km}$, with nine layers between an altitude of $10 \mathrm{~km}$ and $20 \mathrm{~km}$. The impact of the low model top on the planetary wave propagation was studied. If the model top is simply lowered, a large difference occurs in the troposphere as well as in the stratosphere. However, if some readjustment of the wave dissipation is made, the lower-stratospheric circulation becomes more or less realistic (Boville and Chen, 1988). The present study mainly concerns circulation lower than about $25 \mathrm{~km}$, so that the NICAM model, the top of which is at $38 \mathrm{~km}$, can be used.

Moist convection was explicitly calculated using a cloud microphysical scheme (single-moment scheme) with six prognostic variables (Tomita, 2008). Atmospheric radiation, turbulence and ocean processes were calculated using the Model Simulation radiation TRaNsfer code (MSTRN) - X (Nakajima et al., 2000; Sekiguchi and Nakajima, 2008), Mellor-Yamada-Nakanishi-Niino level 2 (Mellor and Yamada, 1982; Nakanishi and Niino, 2006; Noda et al., 2010) and slab ocean models, respectively. The sea surface temperature (SST) was initialized using the National Centers for Environmental Prediction (NCEP) final (FNL) operational global analysis data $\left(1^{\circ} \times 1^{\circ}\right)$ and nudged to the NOAA weekly optimum interpolation SST analysis (Reynolds and Smith, 1994) with a relaxation time of 7 days.

The atmospheric initial data were interpolated from the ECMWF YOTC (Year of Tropical Convection) analysis (Waliser et al., 2012). The simulation period was the 60 days starting from 20 December 2009. During this period, a significant MJO event took place (Waliser et al., 2012), and this MJO event was targeted in a model intercomparison project (http://yotc.ucar.edu/mjo/ vertical-structure-and-diabatic-processes-mjo). The cloud properties in the upper troposphere (UT) have been evaluated in comparison with satellite observations (e.g. Inoue et al., 2010; Kodama et al., 2012).

In the present study, winds (zonal, meridional and vertical), temperature, specific humidity, diabatic heating rates (by cloud microphysics and solar radiation), snow, ice and graupel contents, and column-integrated cloud fraction were analysed. The cloud fraction data are two-dimensional 


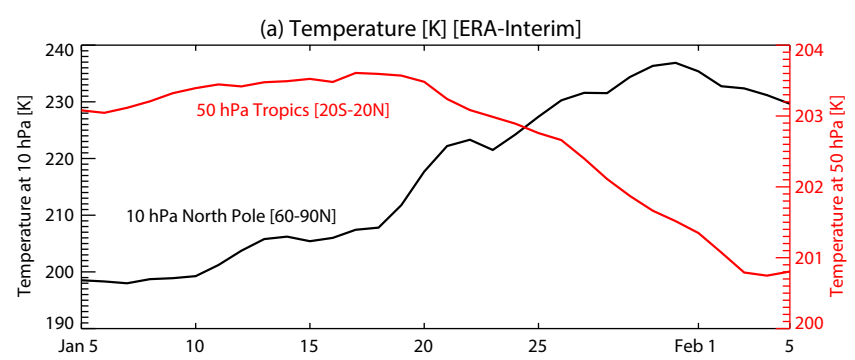

(b) V'T' @ 100hPa, Lat:45N-75N [ERA-interim]

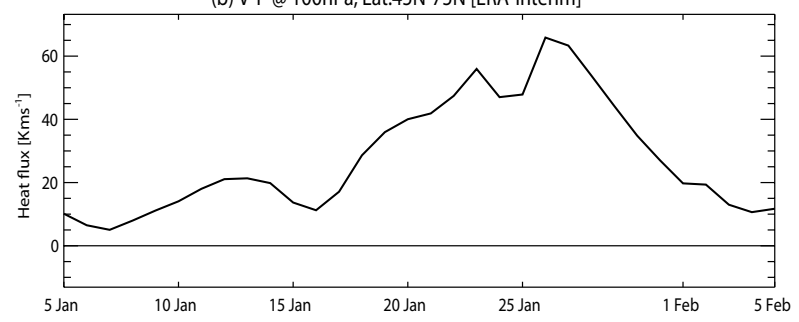

(c) OLR $\left[\mathrm{W} / \mathrm{m}^{2}\right][\mathrm{NOAA}$

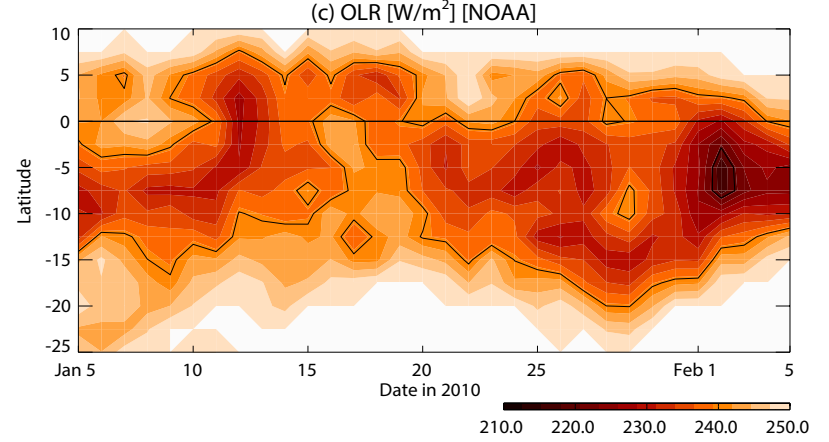

Figure 1. (a) Time series of observed zonal mean temperature (K) in the northern high latitude at $10 \mathrm{hPa}$ (black line) and tropical at $50 \mathrm{hPa}$ (red line) from 5 January to 5 February 2010 . Note the different temperature scales for the polar (left) and tropical (right) regions. (b) Time series of observed zonal mean eddy heat flux $\left(\mathrm{Km} \mathrm{s}^{-1}\right)$ at $100 \mathrm{hPa}$ averaged between $45^{\circ} \mathrm{N}$ and $75^{\circ} \mathrm{N}$. (c) Timelatitude $\left(25^{\circ} \mathrm{S}-10^{\circ} \mathrm{N}\right)$ section of NOAA observed zonal mean OLR $\left(\mathrm{W} \mathrm{m}^{-2}\right)$. The horizontal line indicates the equator.

(longitude-latitude), and the others are three-dimensional. Snapshot data were archived at $3 \mathrm{~h}$ intervals, except for cloud fraction (hourly mean) and diabatic heating rate (daily mean). All the output variables were daily averaged and converted into $1^{\circ}$ data sets.

\section{Results}

\subsection{Stratospheric sudden warming simulated by NICAM}

In the real atmosphere, the SSW in the boreal hemisphere occurred during January 2010 (cf. Dörnbrack et al., 2012). The temperature increased by $+35 \mathrm{~K}$ in the northern polar region and decreased by $-2.5 \mathrm{~K}$ in the tropical lower stratosphere (LS), with increasing wave activity at middle latitudes
(Fig. 1a and b). In the NICAM simulation, minor stratospheric warming spontaneously occurred in January 2010, although the date on which the tropical lower-stratospheric (approximately $50-80 \mathrm{hPa}$ ) temperature started decreasing was approximately 5 days earlier than in the real atmosphere. The temperature rose in the polar region but decreased in the tropics (Fig. 2a) because enhanced wave activity at middle latitudes (Fig. 4c) induced downwelling in the polar region and upwelling in the tropics in the stratosphere. The temperature variation was comparable to that in the real atmosphere: the temperature rose by approximately $+25 \mathrm{~K}$ in the northern polar region and fell by $-1.5 \mathrm{~K}$ in the tropics after 7 January.

The tropical averaged temperature in the LS decreased gradually from 14 January; the latitude-time section of the LS temperature (Fig. 2b) shows that cooling on the south side of the equator starts around 14 January, before that on the north side. In the tropical troposphere, the centre of the region of active convection shifted southward from $5^{\circ} \mathrm{S}$ to $15^{\circ} \mathrm{S}$ after 14 January, when the LS started cooling. The latitude of minimum temperature (Fig. $2 \mathrm{~b}$ ) was located to the south of the convective region (around $25^{\circ} \mathrm{S}$; Fig. 2c); here, the LS upwelling was enhanced in period (ii).

After 21 January, cooling occurred over the wide tropics $\left(30^{\circ} \mathrm{S}-30^{\circ} \mathrm{N}\right)$ with an equatorially symmetric structure (Fig. 2b). The largest column-integrated cloud fraction occurred in association with the cooling in the tropical LS around 24 January. Note that the column-integrated cloud fraction includes both convective and upper-level thin clouds. The convective clouds are measured by outgoing longwave radiation (OLR). The region of minimum OLR shifted southward from $5^{\circ} \mathrm{S}$ to $12.5^{\circ} \mathrm{S}$ after 14 January. The upper-level clouds (ice clouds) also shifted southward and extended farther southward $\left(15^{\circ} \mathrm{S}\right)$ compared to convective clouds (Fig. 2d). In the real atmosphere, the convective region was shifted southward around 20 January and enhanced around 2 February (Fig. 1c). The convective initiation of the MJO event took place over the western Indian Ocean at the end of December 2009, and the MJO propagated eastward during January 2010. The SSW occurred when the MJO passed over the maritime continent. In the simulation, the MJO was weaker than in the observations, the eastward propagation started at the end of period (ii) or the beginning of period (iii) (figure is not shown). Further, the equatorial convection in the simulation (and the observation) was suppressed during period (ii) (when convection was passing over the maritime continent in the observation) because the convective activity regions shifted southward to the equatorial southern hemisphere. It is suggested that the convection behaviour cannot be explained only by an eastward travelling convective signal, such as MJO. Thus, the effects of the MJO are expected to be small for the simulated convective variations during the target 2 weeks.

We divided the period into three consecutive 7-day periods according to the LS tropical temperature (Fig. 2): period (i) (7-13 January) is prior to the start of the cooling event; pe- 

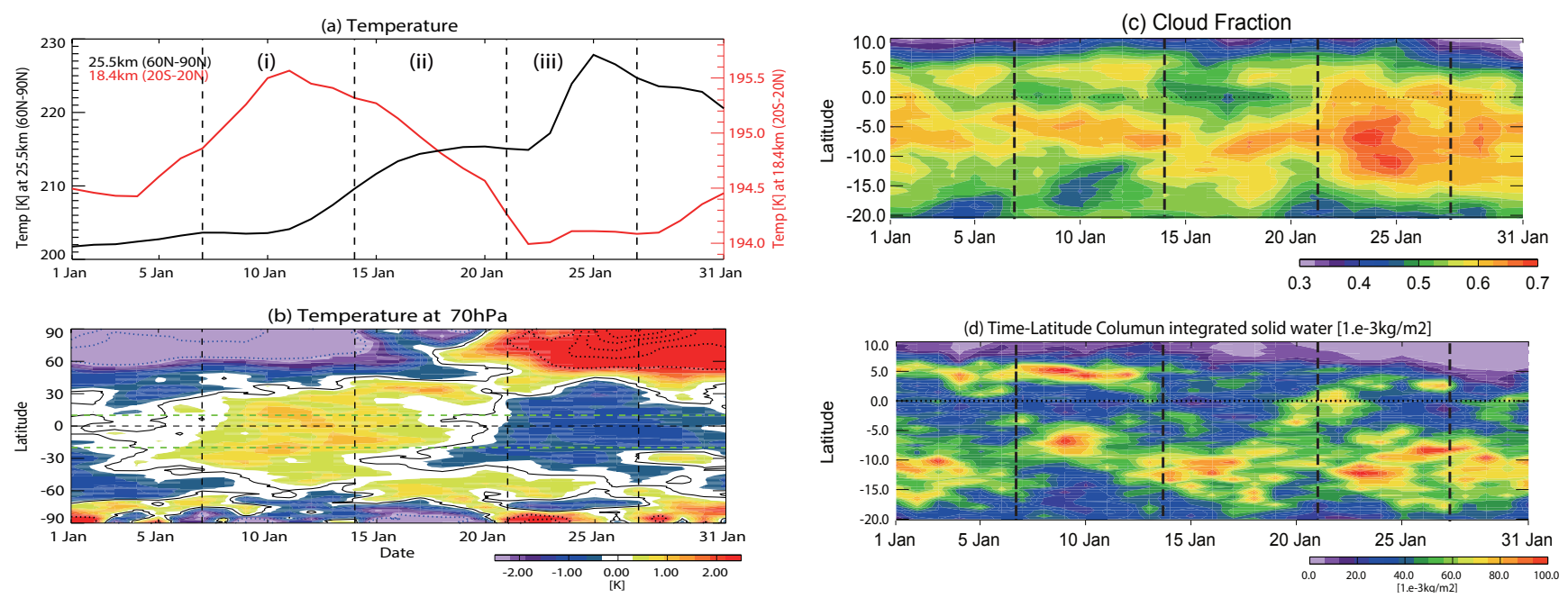

Figure 2. (a) Same as Fig. 1a but for simulated zonal mean temperature from 1 to 31 January 2010. (b) Time-latitude $\left(90^{\circ} \mathrm{N}-90^{\circ} \mathrm{S}\right)$ section of simulated temperature anomaly $(\mathrm{K})$ at $70 \mathrm{hPa}$ with respect to the January 2010 monthly mean at each latitude. The solid contour indicates zero anomaly and the dotted contours indicate $-2.5 \mathrm{~K}$ and $2.5 \mathrm{~K}$. The light green horizontal dashed lines indicate the latitudinal region of (c) and (d). (c) Time-latitude $\left(20^{\circ} \mathrm{S}-10^{\circ} \mathrm{N}\right)$ section of simulated zonal mean column-integrated cloud fraction. (d) Same as (c) but for columnintegrated ice cloud $\left(10^{-3} \mathrm{~kg} \mathrm{~m}^{-2}\right)$. The four vertical dashed lines in (a-d) are 7, 14, 21 and 27 January; the periods between the lines are the (i) initial, (ii) transition and (iii) mature phases. The horizontal dashed lines in (b, $\mathbf{c}$ and $\mathbf{d})$ indicate the equator.

riod (ii) (14-20 January) is characterized by a cooling trend; while period (iii) (21-27 January) is the period of peak cooling. These periods could be regarded as the initiation, transition and mature phases of the SSW impact on the tropics, respectively.

\subsection{Connection between stratospheric and tropospheric meridional circulation}

Ueyama et al. (2013) demonstrated that the tropical temperature tendency at $70 \mathrm{hPa}(\mathrm{LS})$ is closely related to the strength of the stratospheric meridional circulation. To investigate in more detail the structure of the coupling between the stratospheric and tropospheric circulation, the temporal correlation coefficient between the tropical mean vertical velocity at $70 \mathrm{hPa}$ and the zonal mean vertical velocity at each level was calculated (Fig. 3a). The vertical velocity at $100 \mathrm{hPa}$ (TTL) was not correlated with that at $70 \mathrm{hPa}$, except near $20^{\circ} \mathrm{S}$. However, better correlation is found in the deep troposphere and the LS in a latitudinal zone of $20^{\circ} \mathrm{S}-10^{\circ} \mathrm{S}$, where the convection is enhanced in period (ii), as shown in Fig. 2c. These features are also confirmed in time-longitude sections (not shown).

Variation of the vertical velocity in the troposphere usually accompanies a change in cloud formation. The difference in diabatic heating due to cloud microphysics between periods (ii) and (i) is displayed in Fig. 3b. A large change in the diabatic heating is found between 20 and $10^{\circ} \mathrm{S}$, corresponding to the zone of enhanced upwelling from the surface to the TTL. In the TTL (at $100 \mathrm{hPa}$ ), an increase of the diabatic heating extended all over the tropics, including the Northern
Hemisphere (NH). This zone of increased diabatic heating just below $70 \mathrm{hPa}$ corresponds to a zone of decreased water vapour (Fig. 3c), as upwelling induces adiabatic cooling leading to sublimation of water vapour. The cooling trend in the TTL was evident over the wide tropics $\left(30^{\circ} \mathrm{S}-30^{\circ} \mathrm{N}\right)$ (Fig.2b).

Cirrus cloud forms in the TTL $\left(30^{\circ} \mathrm{S}-20^{\circ} \mathrm{N}\right)$ after the onset of the SSW, although higher correlations of vertical wind with that over the tropical LS are limited to within the convective region $\left(20-10^{\circ} \mathrm{S}\right)$. In other words, the low correlation between the vertical motion in the LS and that in the TTL (around $100 \mathrm{hPa}$ ) implies that the mechanisms of the formation of ice clouds in the TTL were different from those of convective clouds in the tropical deep troposphere. The next subsection will describe the detailed mechanism of ice cloud formation in the TTL.

Figure $3 \mathrm{~b}$ and $\mathrm{c}$ also show that the increased diabatic heating in the deep troposphere occurs in association with an increase in water vapour in the lower troposphere. This is indicative of positive feedback between convective activity and low-level moisture convergence in the lower troposphere (EK10) over the tropical SH in period (iii), as illustrated in Fig. 2c.

\subsection{Downward propagation of dynamical signal through the TTL}

Time-altitude sections of the temperature tendency, static stability and anomalous vertical velocity are displayed in Fig. 4. The static stability is defined by $\frac{g}{\theta} \frac{\partial \theta}{\partial z}$, where $g$ is the acceleration due to gravity $\left(9.81 \mathrm{~m} \mathrm{~s}^{-2}\right)$ and $\theta$ is poten- 

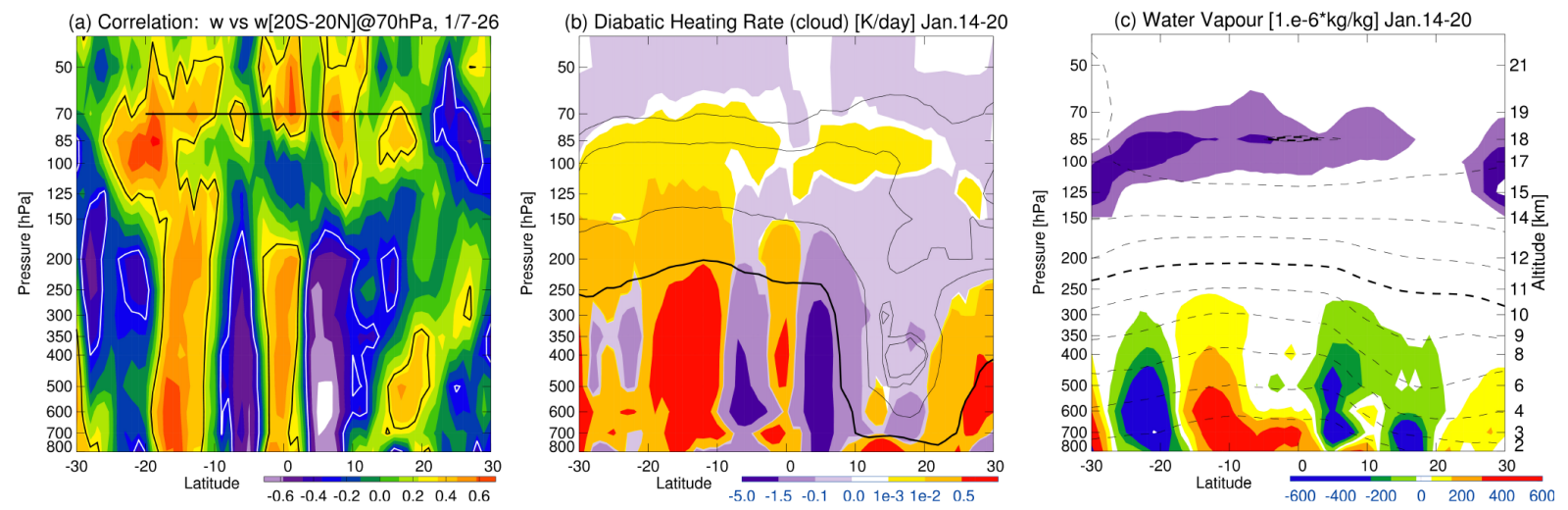

Figure 3. (a) Latitude-pressure sections of correlation between the vertical wind averaged over $20^{\circ} \mathrm{S}-20^{\circ} \mathrm{N}$ at $70 \mathrm{hPa}$ (thick line) and vertical wind at each level and latitude for the period of 7-26 January. Latitude-pressure sections of (b) latent heating rate due to cloud formation $\left(\mathrm{K} \mathrm{day}^{-1}\right)$ (contours) and (c) the water vapour concentration $\left(10^{-6} \mathrm{~kg} \mathrm{~kg}^{-1}\right)$ (dashed contours) averaged between 14 and $20 \mathrm{January}$. The thin contours in (b) are values of $10^{-3} \times 10^{i}(i=0,1,2)\left(\mathrm{Kday}^{-1}\right)$. The thick contour is $1.0\left(\mathrm{Kday}^{-1}\right)$. The dashed contours in $(\mathbf{c})$ are values of $10^{4} \times 10^{i / 3}(i=0,1,2, \ldots, 10)\left(10^{-6} \mathrm{~kg} \mathrm{~kg}^{-1}\right)$; the thick dashed contours indicate 4.6 and $100\left(10^{-6} \mathrm{~kg} \mathrm{~kg}^{-1}\right)$. Anomalies with respect to the 7-13 January average are shown by colour shading. The light and heavy purple in (c) indicate values of $-0.3\left(10^{-6} \mathrm{~kg} \mathrm{~kg}^{-1}\right)$ and below and $-0.6\left(10^{-6} \mathrm{~kg} \mathrm{~kg}^{-1}\right)$ and below, respectively.

tial temperature $(\mathrm{K})$. Variables are averaged over the tropical band between $20^{\circ} \mathrm{S}$ and the equator, where the convective activity and the upwelling in the TTL showed clear changes during the SSW event (Fig. 3).

Temperatures started decreasing in the LS and the upper TTL (above $17.5 \mathrm{~km}$ ) around 15 January but increased in the troposphere. The region of weak negative temperature trend then propagated downward in the TTL during periods (ii) and (iii). The zone of weaker static stability also descended through the TTL following the negative temperature trend. The anomalous vertical velocity (Fig. 4b) showed a strengthening of the upwelling propagating from the LS to the UT in period (ii), similar to the temperature tendency but with enhancement in the deep troposphere during period (iii), when total column-integrated cloud fraction was the largest (Fig. 2c).

To understand the different characteristics of the variations in temperature tendency and vertical velocity, we investigated the major terms (the term on the left-hand side and first two terms on the right-hand side of the following equation) of the thermodynamic equation in the transformed Eulerian-mean (TEM) framework (Andrews et al., 1987):

$$
\begin{aligned}
& \overline{\frac{\partial T}{\partial t}}=-N^{2} \overline{w^{*}}\left(\overline{\frac{P_{0}}{P}}\right)^{-\kappa}+\overline{\mathrm{DH}}-\overline{v^{*}} \frac{\overline{\partial T}}{a}-\frac{1}{\partial \phi} \frac{\partial}{\rho_{0} z} \\
& {\left[\rho_{0}\left(\overline{\frac{v^{\prime} T^{\prime}}{a \frac{\partial T}{\partial z}}} \frac{\partial T}{\partial \phi}+\overline{w^{\prime} T^{\prime}}\right)\right] .}
\end{aligned}
$$

Here, $T$ is temperature, $N$ is the Brunt-Väisälä frequency, $w^{*}\left(v^{*}\right)$ is the vertical (meridional) component of residual velocity, DH is the diabatic heating rate (cloud microphysics and radiation), $P\left(P_{0}\right)$ is (reference) pressure and $\kappa$ is $R / C_{p}$
(0.286) (where $R$ is the gas constant and $C_{p}$ is the specific heat at constant pressure). The third and fourth terms of the right-hand side of the equation are meridional advection and diffusion by waves and eddies, respectively.

The temperature tendency agrees quite well with the adiabatic cooling rate at $20 \mathrm{~km}$ (LS) (Fig. 4d). The evolution of these curves matches that of the eddy heat flux $\left(\overline{v^{\prime} T^{\prime}}\right)$ at $100 \mathrm{hPa}$ averaged over the extratropical NH (Fig. 4c). Note also that the radiative diabatic heating rate remains almost constant at $+0.5 \sim 0.6 \mathrm{~K} \mathrm{day}^{-1}$, which balances the third and fourth terms on the right-hand side of the above thermodynamic equation.

In the bottom part of the TTL $(14.3 \mathrm{~km}$ in Fig. $4 \mathrm{e})$, the adiabatic and diabatic heating were almost in balance, while the adiabatic cooling associated with the stratospheric upwelling drove the temperature tendency at greater heights (above $14.3 \mathrm{~km}$ ). Meanwhile, the heat balance in the TTL was also related to the longitudinal distributions of diabatic heating due to cloud microphysics and solar (shortwave) radiation.

Figure $5 \mathrm{a}$ and $\mathrm{b}$ show the horizontal variation of the latent heating rate due to cloud microphysics as an indicator of cloud formation at the bottom of the TTL $(14.3 \mathrm{~km})$. Figure $5 \mathrm{c}$ and $\mathrm{d}$ show the longitude-height section of vertical velocity averaged over $20^{\circ} \mathrm{S}-$ Equator. Left and right panels display the averages during periods (i) and (ii), respectively. In period (i), before the SSW event started, clouds formed mainly along the intertropical convergence zone (ITCZ) and over the southwestern Pacific region in the UT, which extended up to the TTL. In the TTL, clouds were also found over equatorial Africa and South America. 

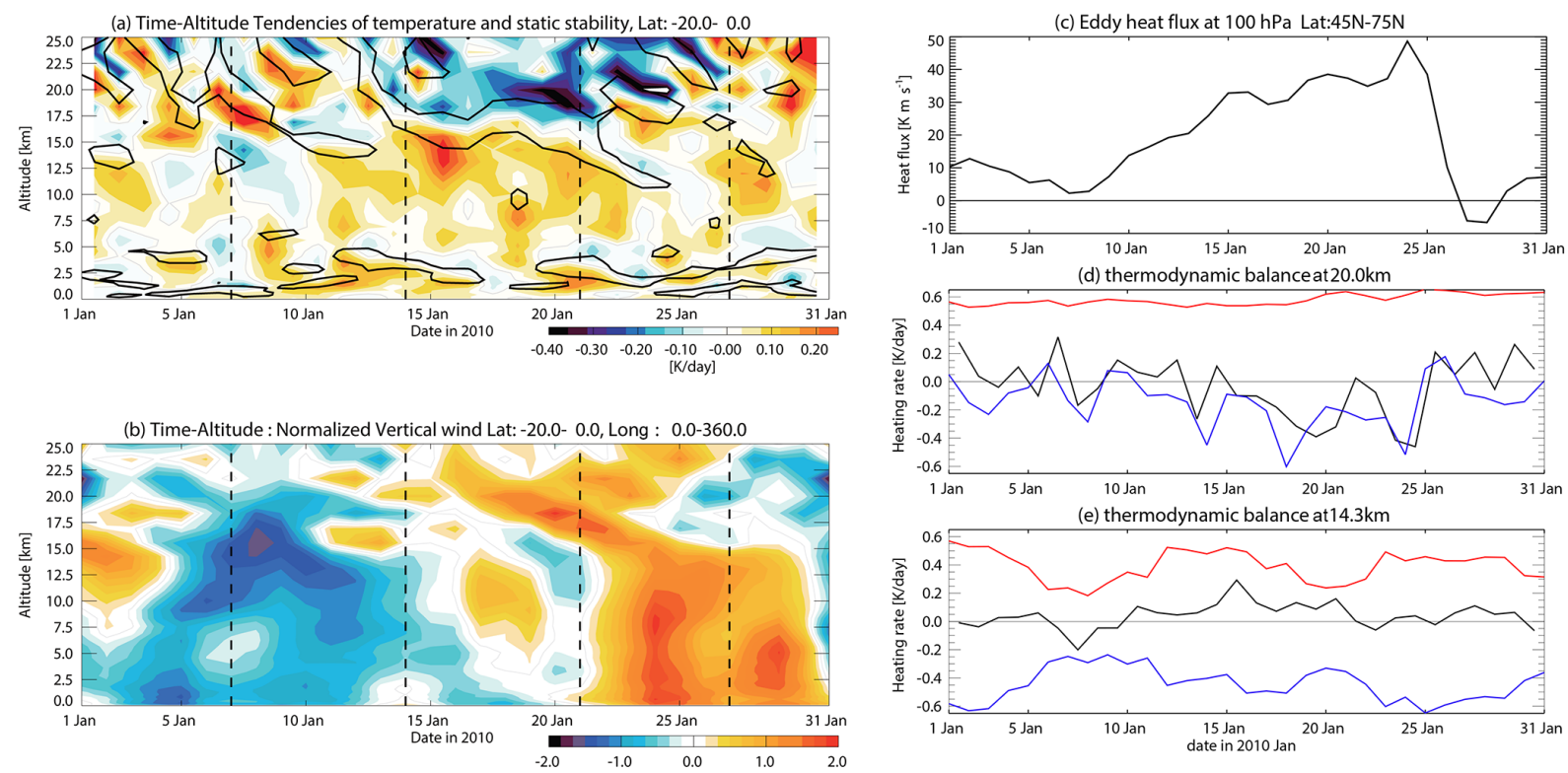

Figure 4. Time-altitude section of (a) temperature tendency $\left(\mathrm{Kday}^{-1}\right)$ (colour shading) and tendency of static stability with value of -0.02 $\left(10^{-4} \mathrm{~s}^{-2} \mathrm{day}^{-1}\right)$ shown by black contours and (b) anomalous normalized vertical velocity averaged between $20^{\circ} \mathrm{S}$ and equator from 1 to 31 January 2010. The normalized values are obtained by dividing them by the standard deviation at each altitude. (c) Time series of zonal mean eddy heat flux $\left(\mathrm{Km} \mathrm{s}^{-1}\right)$ at $100 \mathrm{hPa}$ averaged between $45^{\circ} \mathrm{N}$ and $75^{\circ} \mathrm{N}$. Panels $(\mathbf{d}, \mathbf{e})$ show the time series of thermodynamic balance at 14.3 and $20.0 \mathrm{~km}$ averaged between $20^{\circ} \mathrm{S}$ and Equator. The black, red and blue lines indicate temperature tendency $(\partial T / \partial t)$, diabatic heating rate due to cloud microphysics and radiation, and adiabatic heating rate due to residual vertical velocity $\left(-N^{2} \omega^{*}\right)$, respectively.

When the LS in the southern tropics started to cool in period (ii), convective activity in the TTL shifted southward and increased along the latitudes $20-10^{\circ} \mathrm{S}$ (Fig. 3b), particularly over the southwestern Pacific, southwestern Indian Ocean and coastal regions of South America. The development of convective intensity and depth from period (i) to (ii) is apparent in the pressure-longitude section of vertical velocity, especially over the western Pacific and the western Indian Ocean (Fig. $5 \mathrm{c}$ and d). The upward motion above the TTL, especially at $85 \mathrm{hPa}$, became dominant in period (ii).

Thus, diabatic heating and vertical motion associated with deep convection with zonally asymmetric distributions influenced the heat balance in the UT and TTL, whereas in the LS the effects of zonally symmetric vertical motion were dominant (as indicated by Figs. 4d, e and 5c, d).

\section{Summary and discussion}

The present study investigates stratospheric dynamical impacts on the tropical tropospheric convection during an SSW event from the view point of thermodynamic balance in the TTL. As a pilot study, simulation data from a global nonhydrostatic model (NICAM), where moist convection is explicitly represented, were analysed. The impact of the SSWs has been confirmed in a previous ensemble mean forecast study of a conventional GCM by implementing a perturbation in the extratropical initial field to produce or to suppress the SSW (Kodera et al., 2011). Note, however, that the cumulus convection is parameterized in this GCM, so that we further need to verify whether similar results are obtained by using a global cloud resolving model. The model reproduced the observed processes during SSW: convective activity in the tropical SH was enhanced following an amplification of extratropical planetary wave activity in the winter $\mathrm{NH}$. Vertical velocity and diabatic heating, which are difficult to observe, are intensively investigated.

The stratosphere-troposphere connection was detected in the correlation coefficient between the tropical stratospheric upwelling and the vertical velocity in the tropical troposphere. The highest correlation was found in the $\mathrm{SH} 20-10^{\circ} \mathrm{S}$ latitudinal band (Fig. 3a), where the upwelling branch of BD circulation in the summer hemisphere is located for this case. Particularly large variation is found over in Fig. 5 over the southwestern Indian Ocean, the southwestern Pacific and the coastal region of Australia, similar to the observation (Fig. 3 in Kodera et al., 2014).

Although upwelling in the troposphere occurs following that of the stratosphere, it was not produced by the same process (Fig. 4). Vertical velocity over the wide tropics (e.g. $30^{\circ} \mathrm{S}-30^{\circ} \mathrm{N}$ ) in the LS is mainly driven by extratropical planetary waves (Ueyama et al., 2013; Abalos et al., 2013), but that in the UT was affected mainly by deep convection in a more restricted zone around $20-10^{\circ} \mathrm{S}$. 
(a) Diabatic Heating Rate (cloud) [K/day] at 14.3 [km] Jan.07-13

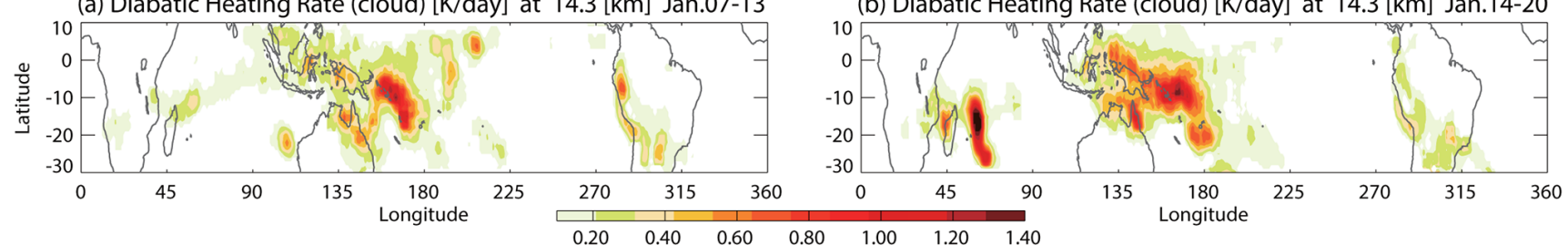

(c) vertical wind $[\mathrm{m} / \mathrm{s}]$ Jan.07-13 Lat:-20.0/ 0.0

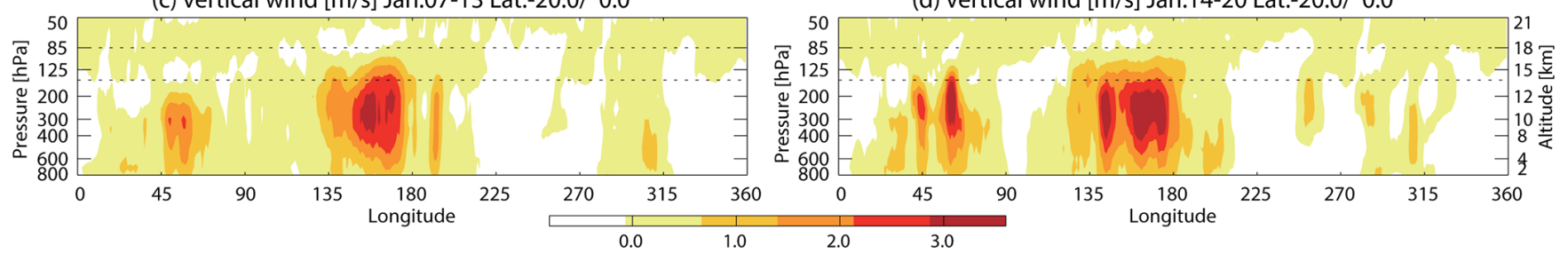

Figure 5. Maps of diabatic heating rate from cloud microphysics $\left(\mathrm{Kday}^{-1}\right)$ at $14.3 \mathrm{~km}(\mathbf{a}, \mathbf{b})$ averaged over 7-13 January (left, a) and $14-$ 20 January (right, b). The panels $(\mathbf{c}, \mathbf{d})$ show longitude-pressure sections of vertical wind $\left(\mathrm{m} \mathrm{s}^{-1}\right)$ averaged between $20^{\circ} \mathrm{S}$ and equator on 7-13 and 14-20 January, respectively. The vertical wind data are smoothed by applying a weighting function of five-degree-longitude width. The horizontal dotted lines in (c, d) show the $85 \mathrm{hPa}$ and $150 \mathrm{hPa}$ pressure levels for reference.

The impact of increased stratospheric upwelling can be seen as a decrease in water vapour around the tropical tropopause region, and the other is an increase in water vapour around the upwelling branch of the Hadley cell in the summer hemisphere $\left(15^{\circ} \mathrm{S}\right)$ (Fig. $\left.3 \mathrm{~b}\right)$. The former effect around the tropopause is due to a condensation of water vapour by large-scale cooling associated with enhanced tropical upwelling in the lower stratosphere ( $\mathrm{Li}$ and Thompson, 2013). The other effect can be attributed to an increased overshooting and deep convective activity due to decreased static stability in the TTL as a consequence of adiabatic cooling in the lower stratosphere and diabatic heating in the TTL (Fig. 4).

This impact of decreased stability on the convective activity was studied by Chae and Sherwood (2010) with a nonhydrostatic regional model with a $28 \times 600 \mathrm{~km}$ domain. A similar effect is confirmed for the present case. Moreover, the global model also showed the occurrences of more complex processes: the large-scale organization of convective activity and the associated decrease in water vapour in the tropical NH (Fig. 3). The large-scale change in convection took place as a mesoscale organization of convective systems, such as a tropical cyclone or storms (Fig. 5); this can also be seen in observational results (Kodera et al., 2014). To clarify such complex processes, we further need specific numerical experiments, which should be carried out by using an updated version of the global non-hydrostatic model.

There is uncertainty in the present results because of single-simulation analysis. To clarify further in the near future the causal relationship between the tropical troposphere change and the stratospheric circulation change, statistical analysis using the longer simulation and/or the comparison study by the simulations with/without SSW will be helpful.
Acknowledgements. The NICAM simulation was performed on the Earth Simulator. The authors would like to thank Chihiro Kodama at the Japan Agency for Marine-Earth Science and Technology (JAMSTEC) for his useful comments. This study was supported by JSPS KAKENHI Grant-in-Aid for Young Scientists (B), number 23710025, and JSPS KAKENHI Grant-in-Aid for Scientific Research (C), number 25340010.

Edited by: P. Haynes

\section{References}

Abalos, M., W.J. Randel and E. Serrano : Dynamical forcing of subseasonal variability in the tropical Brewer-Dobson circulation, J. Atmos. Sci., in press.

Andrews, D. G., Holton, J. R., and Leovy, C. B.: Middle Atmosphere Dynamics, Academic Press, Orlando, Florida, 489 pp. 1987.

Boville, Byron A. and Xinhua Cheng, Upper Boundary Effects in a General Circulation Model. J. Atmos. Sci., 45,2591-2606, 1988.

Chae, J.-H. and S. C. Sherwood, Insights into cloud-top height and dynamics from the seasonal cycle of cloud-top heights observed by MISR in the West Pacific region. J. Atmos. Sci., 67, 248-261, 2010.

Dörnbrack, A., Pitts, M. C., Poole, L. R., Orsolini, Y. J., Nishii, K., and Nakamura, H.: The 2009-2010 Arctic stratospheric winter general evolution, mountain waves and predictability of an operational weather forecast model, Atmos. Chem. Phys., 12, 36593675, doi:10.5194/acp-12-3659-2012, 2012.

Eguchi, N. and Kodera, K.: Impact of the 2002, Southern Hemisphere, stratospheric warming on the tropical cirrus clouds and convective activity, Geophys. Res. Lett., 34, L05819, doi:10.1029/2006GL028744, 2007. 
Eguchi, N. and Kodera, K.: Impacts of stratospheric sudden warming event on tropical clouds and moisture fields in the TTL: a case study, SOLA, 6, 137-140, doi:10.2151/sola.2010-035, 2010.

Emanuel, K., Solomon, S., Folini, D., Davis, S., and Cagnazzo, C.: Influence of tropical tropopause layer cooling on Atlantic hurricane activity, J. Climate, 26, 2288-2301, 2013.

Fueglistaler, S., Dessler, A. E., Dunkerton, T. J., Folkins, I., Fu, Q., and Mote, P. W.: Tropical tropopause layer, Rev. Geophys., RG1004, doi:10.1029/2008RG000267, 2009.

Highwood, E. J. and Hoskins, B. J.: The tropical tropopause, Q. J. Roy. Meteor. Soc., 124, 1579-1604, 1998.

Inoue, T., Satoh, M., Hagihara, Y., Miura, H., and Shmetz, J.: Comparison of high-level clouds represented in a global cloud system-resolving model with CALIPSO/CloudSat and geostationary satellite observations, J. Geophys. Res.-Atmos., 115, D00H22, doi:10.1029/2009JD012371, 2010.

Kodama, C., Noda, A. T., and Satoh, M.: An assessment of the cloud signals simulated by NICAM using ISCCP, CALIPSO, and CloudSat satellite simulators, J. Geophys. Res.-Atmos., 117, D12210, doi:10.1029/2011JD017317, 2012.

Kodera, K., Funatsu, B. M., Claud, C., and Eguchi, N.: The role of convective overshooting clouds in tropical stratospheretroposphere dynamical coupling, Atmos. Chem. Phys. Discuss., 14, 23745-23761, doi:10.5194/acpd-14-23745-2014, 2014.

Kodera, K., Mukougawa, H., and Kuroda, Y.: A general circulation model study of the impact of a stratospheric sudden warming event on tropical convection, SOLA, 7, 197-200, doi:10.2151/sola.2011-050, 2011.

Li, Y. and Thompson, D. W. J.: The signature of the stratospheric Brewer-Dobson circulation in tropospheric clouds, J. Geophys. Res.-Atmos., 118, 3486-3494, doi:10.1002/jgrd.50339, 2013.

Mellor, G. L. and Yamada, T.: Development of a turbulent closure model for geophysical fluid problems, Rev. Geophys., 20, 851875, 1982.

Nakajima, T., Tsukamoto, M., Tsushima, Y., Numaguti, A., and Kimura, T.: Modeling of the radiative process in an atmospheric general circulation model, Appl. Optics, 39, 4869-4878, doi:10.1364/AO.39.004869, 2000.

Nakanishi, M. and Niino, H.: An improved Mellor-Yamada level-3 model: its numerical stability and application to a regional prediction of advection fog, Bound.-Lay. Meteorol., 119, 397-407, 2006.

Noda, A. T., Oouchi, K., Satoh, M., Tomita, H., Iga, S., and Tsushima, Y.: Importance of the subgrid-scale turbulent moist process: cloud distribution in global cloud-resolving simulations, Atmos. Res., 96, 208-217, doi:10.1016/j.atmosres.2009.05.007, 2010 .
Ramsay, H. A.: The effects of imposed stratospheric cooling on the maximum intensity of tropical cyclones in axisymmetric radiative-convective equilibrium, J. Climate, 26, 9977-9985, doi:10.1175/JCLI-D-13-00195.1, 2013.

Randel, W. J. and Jensen, E. J.: Physical processes in the tropical tropopause layer and their role in a changing climate. Nat. Geosci., 6, 169-176, doi:10.1038/ngeo1733, 2013.

Reynolds, R. W. and Smith, T. M.: Improved global sea surface temperature analyses using optimum interpolation, J. Climate, 7, 929-948, 1994.

Satoh, M., Matsuno, T., Tomita, H., Miura, H., Nasuno, T., and Iga, S.: Nonhydrostatic icosahedral atmospheric model (NICAM) for global cloud resolving simulations, J. Comput. Phys., 227, 3486-3514 doi:10.1016/j.jcp.2007.02.006, 2008.

Satoh, M., H. Tomita, H. Yashiro, H. Miura, C. Kodama, T. Seiki, A. T. Noda, Y. Yamada, D. Goto, M. Sawada, T. Miyoshi, Y. Niwa, M. Hara, T. Ohno, S. Iga, T. Arakawa, T. Inoue, H. Kubokawa, 2014: The Non-hydrostatic Icosahedral Atmospheric Model: description and development. Prog. Earth Planet. Sci., 1, 18. doi:10.1186/s40645-014-0018-1, 2014.

Sekiguchi, M. and Nakajima, T.: A k-distribution-based radiation code and its computational optimization for an atmospheric general circulation model, J. Quant. Spectrosc. Ra., 109, 2779-2793, 2008.

Thuburn, J. and Craig, G. C.: Stratospheric influence on tropopause height: the radiative constraint, J. Atmos. Sci., 57, 17-28, doi:10.1175/1520-0469(2000)057-0017:SIOTHT-2.0, 2000.

Tomita, H.: New micorphysical schemes with five and six categories by diagnostic generation of cloud ice, J. Meteorol. Soc. Jpn., 86A, 121-142, 2008.

Ueyama, R., Gerber, E. P., Wallace, J. M., and Frierson, D. M. W.: The role of high-latitude waves in the intraseasonal to seasonal variability of tropical upwelling in the Brewer-Dobson circulation, J. Atmos. Sci., 70, 1631-1648, doi:10.1175/JAS-D-120174.1, 2013.

Waliser, D. E., Moncrieff, M., Burridge, D., Fink, A. H., Gochis, D., Goswami, B. N., Guan, B., Harr, P., Heming, J., Hsu, H.-H., Jakob, C., Janiga, M., Johnson, R., Jones, S., Knippertz, P., Marengo, L., Nguyen, H., Pope, M., Serra, Y., Thorncroft, C., Wheeler, M., Wood. R., and Yuter, S.: The "Year" of tropical convection (May 2008-April 2010): climate variability and weather highlights. B. Am. Meteorol. Soc., 93, 1189-1218, 2012. 